\title{
The effectiveness of $\omega-3$ polyunsaturated fatty acid interventions during pregnancy on obesity measures in the offspring: an up-to-date systematic review and meta-analysis
}

\author{
Mariam Vahdaninia $^{1,2}$ D $\cdot$ H. Mackenzie ${ }^{1} \cdot$ T. Dean $^{1,3} \cdot$ S. Helps ${ }^{1}$
}

Received: 13 April 2018 / Accepted: 18 September 2018 / Published online: 24 September 2018

(c) The Author(s) 2018

\begin{abstract}
Background The potential role of $\omega-3$ long chain polyunsaturated fatty acid (LCPUFA) supplementation during pregnancy on subsequent risk of obesity outcomes in the offspring is not clear and there is a need to synthesise this evidence.

Objective A systematic review and meta-analysis of randomised controlled trials (RCTs), including the most recent studies, was conducted to assess the effectiveness of $\omega-3$ LCPUFA interventions during pregnancy on obesity measures, e.g. BMI, body weight, fat mass in offspring.

Methods Included RCTs had a minimum of 1-month follow-up post-partum. The search included CENTRAL, MEDLINE, SCOPUS, WHO's International Clinical Trials Reg., E-theses and Web of Science databases. Study quality was evaluated using the Cochrane Collaboration's risk of bias tool.

Results Eleven RCTs, from ten unique trials, (3644 children) examined the effectiveness of $\omega-3$ LCPUFA maternal supplementation during pregnancy on the development of obesity outcomes in offspring. There were heterogeneities between the trials in terms of their sample, type and duration of intervention and follow-up. Pooled estimates did not show an association between prenatal intake of fatty acids and obesity measures in offspring.

Conclusion These results indicate that maternal supplementation with $\omega$-3 LCPUFA during pregnancy does not have a beneficial effect on obesity risk. Due to the high heterogeneity between studies along with small sample sizes and high rates of attrition, the effects of $\omega$-3 LCPUFA supplementation during pregnancy for prevention of childhood obesity in the long-term remains unclear. Large high-quality RCTs are needed that are designed specifically to examine the effect of prenatal intake of fatty acids for prevention of childhood obesity. There is also a need to determine specific sub-groups in the population that might get a greater benefit and whether different $\omega$-3 LCPUFA, i.e. eicosapentaenoic (EPA) vs. docosahexanoic (DHA) acids might potentially have different effects.
\end{abstract}

Keywords Systematic review · Meta-analysis · Fatty acids · Fish oil · N-3 LCPUFA · Obesity · Childhood obesity · Adiposity $\cdot$ Body composition · Growth $\cdot$ Infant's growth

\section{Introduction}

The high prevalence of childhood obesity is a serious public health issue and has been reported as a potential risk factor

Mariam Vahdaninia

mariam.vahdaninia@port.ac.uk

1 School of Health Sciences and Social Work (SHSSW), University of Portsmouth, James Watson West, 2 King Richard 1st Road, Portsmouth PO1 2FR, UK

2 Faculty of Health and Social Sciences, Bournemouth University, Poole, UK

3 Research and Enterprise, University of Brighton, Brighton, UK for a range of morbidities and medical conditions that occur later in life [1-4].

The very early days of fetal development, representing a period of substantial developmental plasticity, are thought to impact on health in the life course [5]. The developmental origins of health and disease theory proposes that events/ exposures during this period are a key determinant of the susceptibility to many chronic diseases, including metabolic disorders and obesity [6]. It is well documented that 
the foetus responds to external stimuli in utero and environmental factors such as maternal diet could have effects later in life [7-10]. In this context, interventions that target the nutritional adequacy of women's diet during pregnancy could provide a unique opportunity for early prevention of chronic diseases including obesity.

Over recent decades, the dominance of $\omega-6$ fatty acids in diets, particularly in industrialised countries, has led to suggestions that there maybe an association between the ratio of $\omega-6 / \omega-3$ long chain polyunsaturated fatty acid (LCPUFA) and adipose tissue development during the critical early phases of life [11-13]. While $\omega-6$ LCPUFA may have a stimulatory effect on fat cell development, there is evidence to suggest that $\omega-3$ LCPUFA (DHA and EPA) have anti-obesity effects by decreasing lipid synthesis in cells [14-16]. Human adipose tissue starts to develop in the second trimester of pregnancy [17]. Fat cells acquired at an early stage in life may determine the level of fully differentiated adipocytes later in life, with only approximately $10 \%$ of fat cells being replaced across all ages and at all levels of BMI [18]. Collectively this evidence suggests that maternal intake of $\omega$-3 fatty acids during pregnancy might help to reduce susceptibility to obesity later in life.

The effect of exposure to an increased supply of $\omega-3$ LCPUFA in utero on body composition in the child has been examined in a number of RCTs. However, these have produced conflicting results. This systematic review and metaanalysis aimed to summarise the existing evidence from these RCTs, providing an update to the earlier systematic reviews on this topic [19-24] to include recently published trials.

\section{Methods}

\section{Criteria for considering studies for this review}

\section{Types of studies}

Only randomised controlled trials (RCT, including cluster randomised controlled trials and quasi-randomised controlled trials) with a minimum follow-up of 1 month postnatally were included. The review considered studies which reported body composition data and used maternal $\omega-3$ LCPUFA supplementation. No language or country restrictions were applied.

\section{Types of participants}

Pregnant women and their offspring were considered as the target group for this systematic review. High-risk populations were not excluded.

\section{Types of interventions}

Trials were included that used $\omega-3$ LCPUFA supplementation during pregnancy, irrespective of dose, formulation or mode of delivery and composition, e.g. oil, tablet. Trials were also included if the intervention(s) had been extended after pregnancy either during breast-feeding or directly to the infants or both.

\section{Types of outcomes measures}

Trials were included if they had reported measures of obesity or growth in the offspring, either as a primary or secondary endpoint. Obesity measures were defined as: body mass index (BMI), skin-fold thickness (SFT), obesity, overweight and fat mass. Growth measures (weight, height/length) were considered as secondary outcomes in the review. For trials in which obesity measures were assessed at more than one time point, only the results of the latest follow-up time point was included in the meta-analyses.

\section{Search strategy for identification of studies}

A comprehensive search strategy, including all relevant synonyms for the main concepts, was developed covering the main bibliographic databases. Trials were identified through systematic searches within three main electronic databases, as advised by the Cochrane collaboration [25]:

(a) Cochrane Library (current issue) including:

- Cochrane Database of Systematic Reviews (CDSR)

- CENTRAL (trials)

- DARE

\section{(b) MEDLINE (EBSCOhost)}

(c) SCOPUS

When searching MEDLINE, the subject-specific terms were combined with the Cochrane Highly Sensitive Search Strategy for identifying randomised trials in MEDLINE: sensitivity-maximising version [25]. We adapted the preliminary search strategy for MEDLINE (EBSCOhost) for use in the other databases when relevant. The last search for literature was conducted in January 2018.

The clinical trials registry and WHO platform were searched for ongoing and recently completed trials. Conference proceedings were identified through the ISI Web of Science and, for retrieving theses the British Library E-Theses Online Service was searched. No language or publication status restrictions were imposed. References of included studies were crosschecked for additional studies. 


\section{Data collection and analysis}

\section{Selection of studies}

The main reviewer (MV) along with the second reviewer (HM) screened all the search results against the eligibility criteria and all those which were clearly irrelevant were excluded from further consideration. Thereafter, a tailored eligibility form was used by MV to appraise the retrieved studies, abstract and full text for relevance against the full inclusion criteria. Where there was uncertainty about inclusion of a particular study, this was discussed within the review team (MV, HM, TD) and a consensus was reached about the study eligibility. All the included studies were discussed and approved by the review team.

\section{Data extraction and management}

MV extracted the data using a tailored data extraction form in EPPI Reviewer. Detailed information on study characteristics were recorded. Throughout the data extraction process, any disagreements about the interventions and outcomes were discussed and resolved within the review team. There was no blinding of the authors' name, institutions, journals or the outcomes of the trials during the process. The extracted data were double checked by a second reviewer (HM) for accuracy against the trial reports.

\section{Assessment of risk of bias in included studies}

The risk of bias tool described in the Cochrane Handbook for Systematic Reviews for Interventions was used to appraise the studies [26].

\section{Measurement of treatment effect}

Dichotomous data were analysed as risk ratios or relative risk (RR) with $95 \% \mathrm{CI}$ and continuous data as mean difference or standardised mean difference, with $95 \%$ CI.

\section{Unit of analysis issues}

In trials with more than one intervention arm, multiple pairwise comparisons of intervention groups vs. comparator were avoided. Therefore, data from different intervention arms were pooled for an overall comparison with the control or placebo arm. The weight assigned to the control group was considered as the total number of participants in the comparator group vs. the total number of participants in the combined intervention arms [27].

\section{Dealing with missing data}

All the relevant reported information for the number of missing participants was extracted and if undocumented, this was incorporated into the assessment of risk of bias. No imputed techniques were used for retrieving missing data.

\section{Assessment of heterogeneity}

We used visual inspection of forest plots and the $\chi^{2}$ test to measure statistical heterogeneity between effect sizes of included studies. $I^{2}$ statistics were used to quantify the amount of possible variability in effect estimates that is due to heterogeneity rather than chance $\left(I^{2}<25 \%\right.$ low heterogeneity, $\geq 26 \% I^{2}<74 \%$ moderate heterogeneity, $I^{2} \geq 75 \%$ high heterogeneity). Where there were heterogeneities between trials, a random effect model was used and meta-analysis reported if a moderate heterogeneity was found [25].

\section{Assessment of reporting biases}

Every effort was made to identify unpublished studies through searching abstracts and ongoing trials databases. Publication bias was not assessed due to the small number of included studies [28].

\section{Data synthesis}

We used EPPI Reviewer version 4.4.3.0. for conducting meta-analyses. Dichotomous data (events) and the number of participants were entered. We reported relative risk to describe the study effect [29].

\section{Subgroup analysis and investigation of heterogeneity}

Where possible, sub-group analyses were performed for the control group and duration of follow-up.

\section{Sensitivity analysis}

We did not conduct any sensitivity analysis because of the small number of studies that contributed to meta-analyses.

\section{Results}

Electronic searches yielded a total of 2484 results (Fig. 1). After removal of duplicates and non-relevant studies, the remaining 86 full text papers were assessed against the 
Fig. 1 Study flow diagram, following preferred reporting items for systematic reviews and meta-analyses (PRISMA) criteria

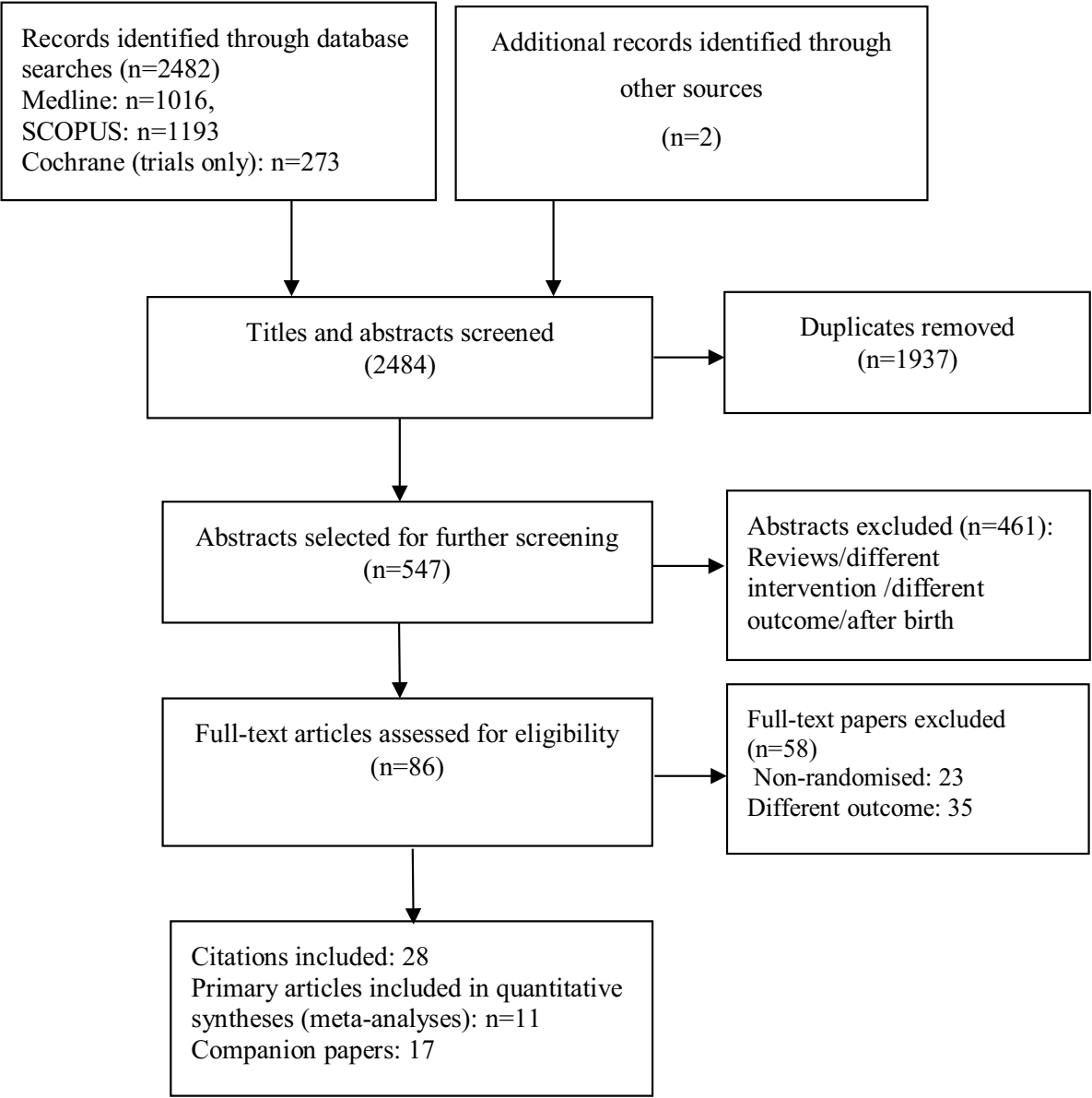

eligibility criteria for this systematic review. Eleven publications from ten unique RCTs were included in the final analyses, including a total of 3644 children. In the case of one trial [53], both the reports of an earlier [52] as well as latest follow-up data [54] were included. This was because the earlier report [52] included 1531 of children from the recruited sample in the original trial [53] whereas the later follow-up at 7 years [54] only included a sub-sample (a small percentage of pregnant women that were initially recruited at randomisation and assessed body composition outcomes in children using BOD POD and Bioelectrical Impedance Spectroscopy (BIS) methods). The characteristics of the included trials, their companion papers and study population are presented in Table 1. One trial was multi-centre (Germany, Hungry and Spain), four studies were conducted in Australia and Germany (two each) and the rest in Norway, Denmark, Mexico, the United States and Iran.

\section{Study design}

All the included trials were parallel RCTs and most trials had two parallel groups while two had three parallel groups, either as intervention or control. The study by Campoy et al. [35] defined interventions as modified fish oil plus vitamin and mineral, fish oil plus 5-methyltetrahydrofolic (MTHF) and 5-MTHF only. In this systematic review, we have only considered modified fish oil component plus vitamin and mineral as the intervention arm compared to placebo. Rytter and colleagues [39] also had two control groups, 'olive oil' or 'no oil'. Olive oil was used as the comparator for metaanalyses in this systematic review. In addition, the nature of the control group (standard diet) in the study by Brei et al. [47] was different from other trials and, therefore, this study was included in the sub-group analyses.

It is important to note that most of the trials were primarily designed to investigate other outcomes in children such as neurological development, maternal insulin sensitivity; and growth measures in the offspring are also reported as secondary end-points [31, 34, 35, 39, 41, 44, 52, 54, 55]. Only two trials $[47,56]$ were originally designed to evaluate the effectiveness of prenatal n-3 LCPUFA supplementation on infant's body composition. The study by Brei et al. [47] was an open label trial and applied a combined intervention approach of fish oil capsules and arachidonic acid-balanced diet (ratio of $\omega-6 / \omega-3$ ) during pregnancy. This study also had a high non-participation rate at the 5 years follow-up. In the study by Ostadrahimi et al. [56], the primary outcome was defined as infants' neurodevelopment status 


\begin{tabular}{|c|c|c|c|c|c|c|}
\hline 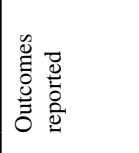 & 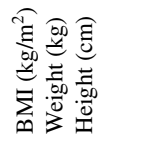 & 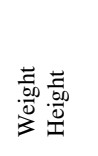 & 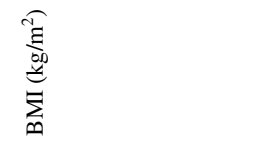 & 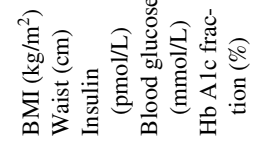 & 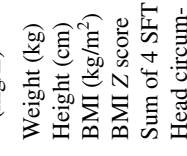 & 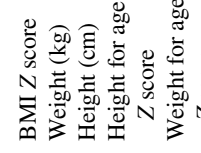 \\
\hline 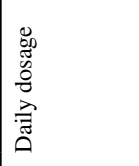 & 裉 & 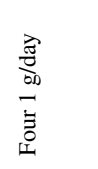 & 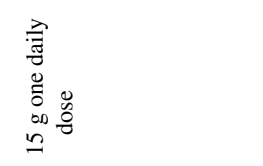 & 吾 & 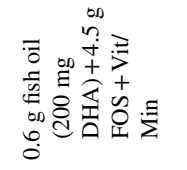 & 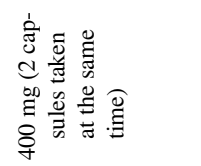 \\
\hline & 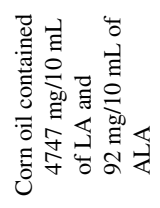 & 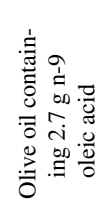 & 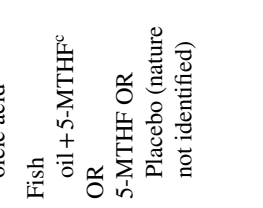 & 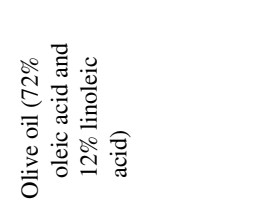 & 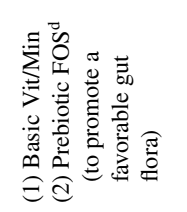 & 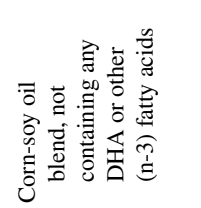 \\
\hline 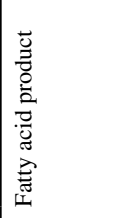 & 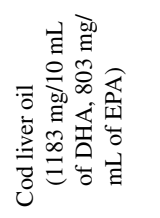 & 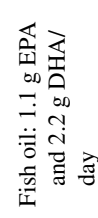 & 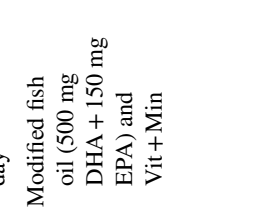 & 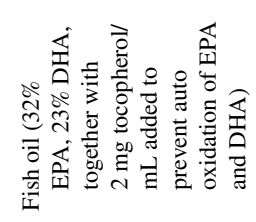 & 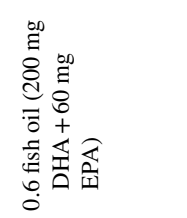 & 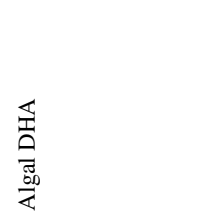 \\
\hline 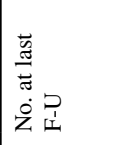 & $\begin{array}{l}\dot{s} \\
\dot{\infty} \\
\infty \\
\ddot{g} \\
\dot{q}\end{array}$ & $\begin{array}{l}\dot{s} \\
\dot{m} \\
\dot{i} \\
\dot{n}\end{array}$ & 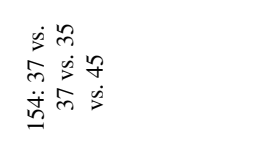 & 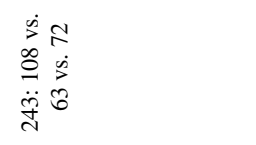 & 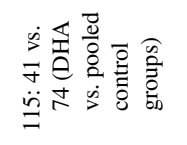 & 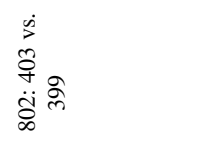 \\
\hline 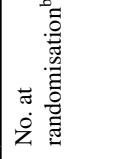 & 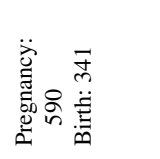 & 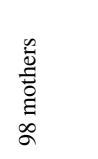 & 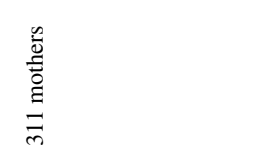 & 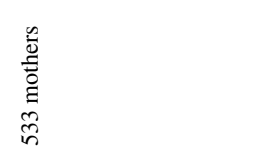 & 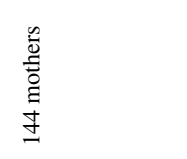 & 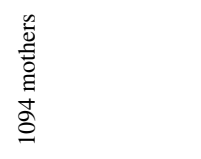 \\
\hline 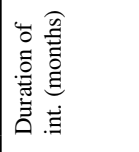 & $\begin{array}{l}n \\
\infty \\
\infty \\
\infty\end{array}$ & $\begin{array}{l}n \\
n \\
q\end{array}$ & $\begin{array}{l}n \\
\stackrel{n}{0} \\
0\end{array}$ & $\begin{array}{l}n \\
\mathfrak{d} \\
\end{array}$ & 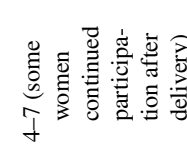 & \\
\hline 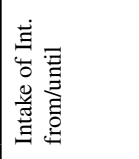 & 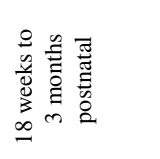 & 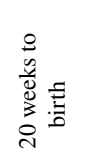 & 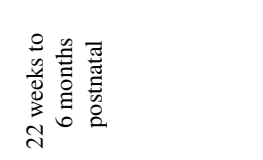 & 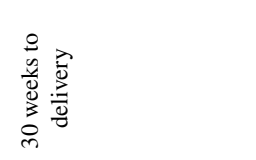 & 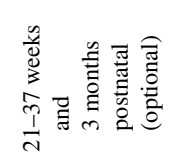 & 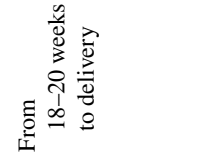 \\
\hline 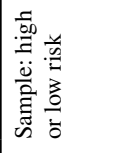 & 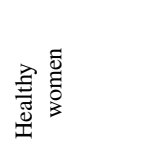 & 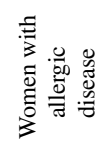 & 焉 & 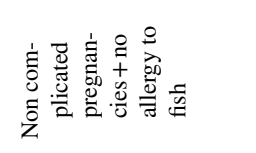 & 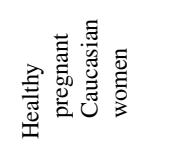 & 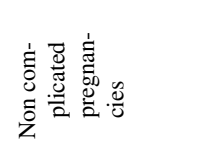 \\
\hline 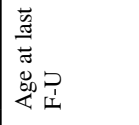 & 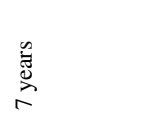 & 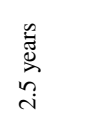 & 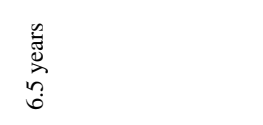 & 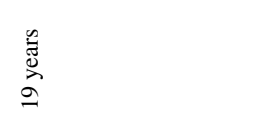 & 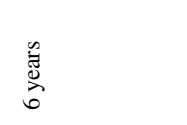 & 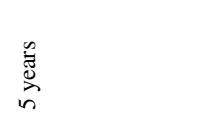 \\
\hline 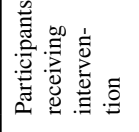 & 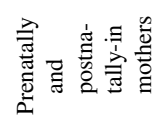 & 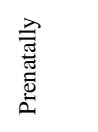 & 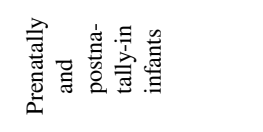 & 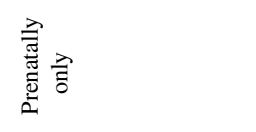 & 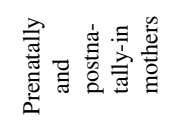 & 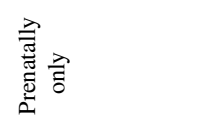 \\
\hline 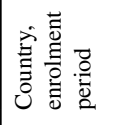 & 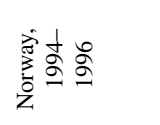 & 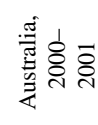 & 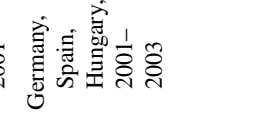 & 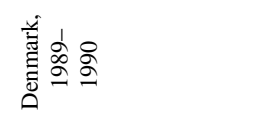 & 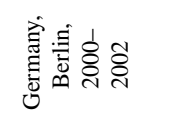 & 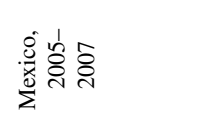 \\
\hline 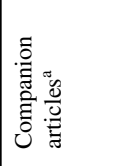 & 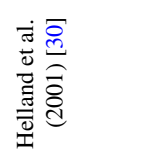 & 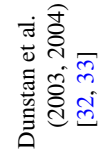 & 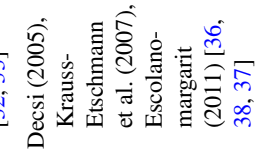 & 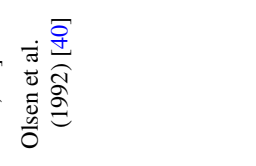 & 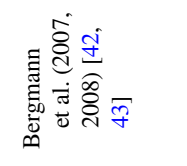 & 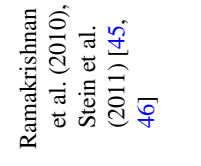 \\
\hline 㩊递 & 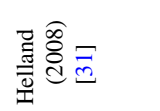 & 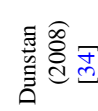 & 总层居 & 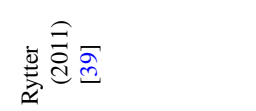 & 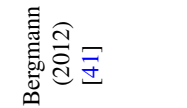 & 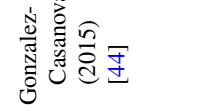 \\
\hline
\end{tabular}




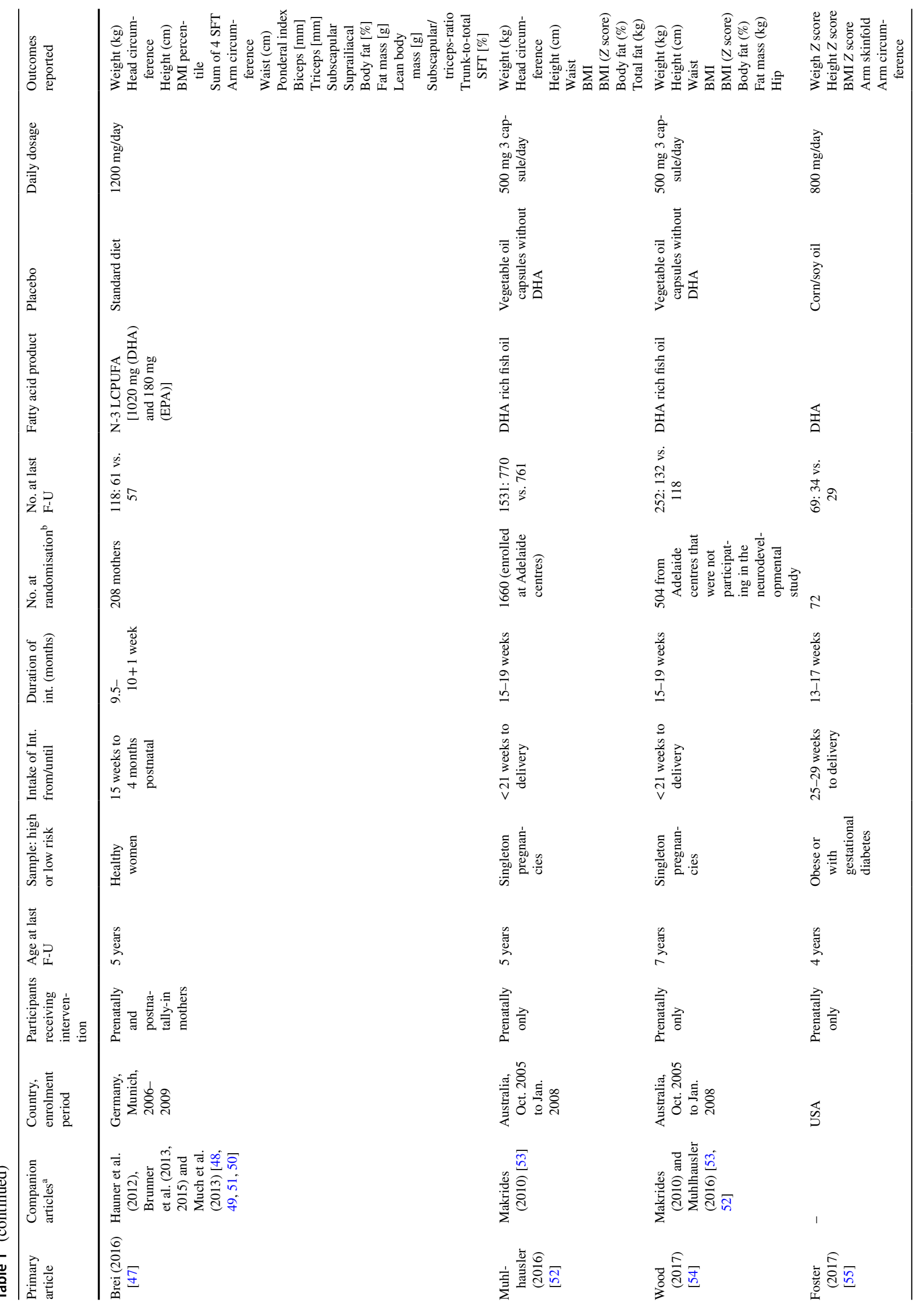




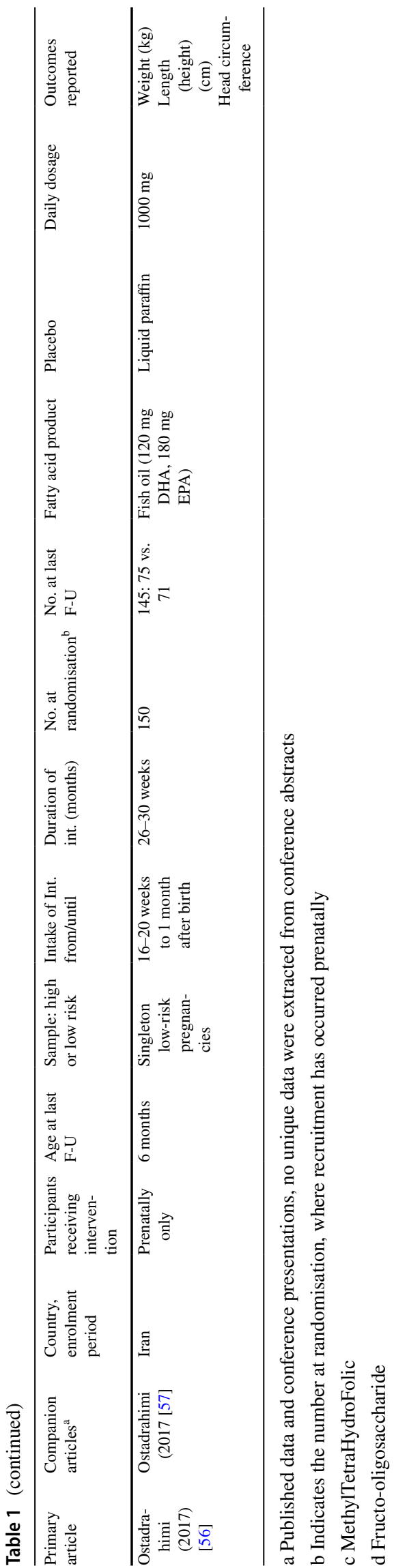

and anthropometric measures were reported as secondary end-points.

\section{Participants and sample sizes}

One trial was conducted in atopic women [34] and another in women who were obese or had a history of gestational diabetes [55]. The remainder of the trials involved healthy pregnant women with non-complicated pregnancies. Studies varied in their sample size at randomisation from 72 [55] to 1660 [52] pregnant women.

\section{Intervention}

With the exception of one study that used algal DHA [44], all other studies used either DHA alone or a combination of EPA and DHA together. In the study by Campoy et al. [35] vitamin and mineral supplements were also used along with the fatty acid component. Furthermore, Brei et al. [47] provided women with $\omega-3$ LCPUFA intervention as well as nutritional counseling, focused on reducing the consumption of n-6 fatty acid (AA) to a moderate level of intake (90 mg AA per day). Six trials supplemented women during pregnancy only and in the case of four trials $[32,35,47$, $56]$ the intervention was continued postnatally with various durations.

Compliance with the intervention was assessed by a variety of methods, including the number of fatty acids capsules ingested, divided by the number the participant should have ingested multiplied by 100; standardised questionnaires at gestation; the percentage of the total number of capsules expected to be consumed; and measuring fatty acids levels in erythrocytes at 30 and 37 gestational week, and 6 weeks postnatally. Four studies did not report the method of measuring adherence to the intervention $[32,41,47,56]$.

\section{Reported obesity outcomes and follow-up duration}

Anthropometric measurements were conducted using standardised references, e.g. WHO reference ranges (including BMI-Z) and by means of standard tools. The definition and diagnosis method for each outcome included in metaanalyses is presented in Table 2. The duration of follow-up in trials ranged from 6 months [56] to 19 years [39]. The most frequently reported obesity measures were BMI and the most reported growth measures were weight and height.

Also, while the trial by Wood [54] reported longerterm follow-up at 7 years from the original study [53], data from the earlier follow-up at 5 years were included in meta-analyses. This was because only $30.3 \%$ of the original sample recruited in the Adelaide centres (504 of 1660 pregnant women that were not participating in the neurodevelopmental study) were eligible to participate in the 
Table 2 Definition of obesity measures included in the meta-analyses and their measurement in individual studies

\begin{tabular}{|c|c|}
\hline Studies & Measurement \\
\hline \multicolumn{2}{|c|}{ Helland (2008) [31], 7 years follow-up } \\
\hline BMI & Not defined \\
\hline Weight & Not defined \\
\hline Height & Not defined \\
\hline \multicolumn{2}{|c|}{ Dunstan (2008) [34], 2.5 years follow-up } \\
\hline Weight & Not defined \\
\hline Height & Not defined \\
\hline \multicolumn{2}{|c|}{ Campoy (2011) [35], 6.5 years follow-up } \\
\hline BMI & Not defined \\
\hline \multicolumn{2}{|c|}{ Rytter (2011) [39], 19 years follow-up } \\
\hline BMI & Not defined \\
\hline \multicolumn{2}{|c|}{ Bergmann (2012) [41], 6 years follow-up } \\
\hline BMI & $\begin{array}{l}\text { Length (height) and weight were measured using Harpenden measuring boards, small measuring } \\
\text { tapes and calibrated Seca balances and BMI was calculated accordingly }\end{array}$ \\
\hline BMI-Z & $\begin{array}{l}\text { BMIs of children from birth to } 6 \text { years were standardised with age-specific means of the World } \\
\text { Health Organisation (WHO) multi-centre growth reference study }\end{array}$ \\
\hline Weight & Using calibrated Seca balances \\
\hline Height & Harpenden measuring boards and small measuring tapes \\
\hline Sum of SFT & Using a Holtain caliper at the midtricipital, the subscapular and the suprailiac measuring point \\
\hline \multicolumn{2}{|c|}{$\begin{array}{l}\text { Gonzalez-Casanova (2015) [44], } 5 \text { years } \\
\text { follow-up }\end{array}$} \\
\hline BMI-Z & $\begin{array}{l}\text { BMI was computed by calculating age at measurement from the date of birth and then converted } \\
\text { to age-specific } Z \text { scores using the } 2006 \text { WHO reference standards }\end{array}$ \\
\hline Weight & Using a Tanita scale to the nearest $10 \mathrm{~g}$ \\
\hline Height & Using a Seca stadiometer to the nearest $1 \mathrm{~mm}$ \\
\hline \multicolumn{2}{|c|}{ Brei (2016) [47], 5 years follow-up } \\
\hline Weight & Using a standard flat scale (Seca Clara), to the nearest $100 \mathrm{~g}$ with the child in a standing position \\
\hline Height & Using a stadiometer, to the nearest $0.5 \mathrm{~cm}$ with the child in a standing position \\
\hline Sum of SFT & $\begin{array}{l}\text { SFTs were measured in triplicate with the use of a Holtain caliper (Holtain Ltd.) at } 4 \text { different } \\
\text { body sites on the left body axis (triceps, biceps, sub- scapular, and suprailiac), at the study } \\
\text { center or at the family's home. The mean of the } 3 \text { measurements was used for the SFT value, } \\
\text { and the sum of the } 4 \text { SFTs was calculated }\end{array}$ \\
\hline Body fat $(\%)$ & Using predictive skinfold regression equations according to Weststrate and Deurenberg \\
\hline Fat mass $(\mathrm{kg})$ & Using predictive skinfold regression equations according to Weststrate and Deurenberg \\
\hline \multicolumn{2}{|c|}{ Muhlhausler (2016) [52], 5 years follow-up } \\
\hline BMI & $\begin{array}{l}\text { Weight using electronic scales (without shoes and in underwear to the nearest } 100 \mathrm{~g} \text { ); height } \\
\text { using a stadiometer without shoes and BMI was calculated accordingly }\end{array}$ \\
\hline BMI-Zs & $\begin{array}{l}\text { The BMI measures for each child were compared with standardized reference charts for the } \\
\text { child's age and sex to calculate their } Z \text { scores }\end{array}$ \\
\hline Weight & As above \\
\hline Height & As above \\
\hline Body fat $(\%)$ & Using the equation as: [fat-free mass - body weightlbody weight] $\times 100$ \\
\hline Fat mass $(\mathrm{kg})$ & Using bioelectrical impedance spectroscopy \\
\hline \multicolumn{2}{|c|}{ Foster (2017) [55], 4 years follow-up } \\
\hline BMI-Z & $\begin{array}{l}\text { Each child was weighed on a digital scale with no shoes and measured to the nearest } 0.1 \mathrm{~kg} \text { with } \\
\text { the procedure repeated. The two weight measurements were required to be within } 0.2 \mathrm{~kg} \text { for } \\
\text { accuracy and precision. Standing height was measured in cm on a stadiometer with a fixed ver- } \\
\text { tical bar and an adjustable headpiece with shoes removed. Height measurement was recorded } \\
\text { to the nearest } 0.1 \mathrm{~cm} \text {, and then the process was repeated. The two height measurements were } \\
\text { required to be within } 0.2 \mathrm{~cm} \text { for accuracy and precision. } Z \text { scores were calculated using the } \\
\text { Centers for Disease Control and Prevention (CDC) reference data }\end{array}$ \\
\hline \multicolumn{2}{|c|}{ Ostadrahimi (2017) [57], 6 months follow-up } \\
\hline Weight & Using a lever scale with a precision of $0.1 \mathrm{~kg}$ (Seca, Germany) \\
\hline
\end{tabular}


Table 2 (continued)

\begin{tabular}{ll}
\hline Studies & Measurement \\
\hline Height & Using a stadiometer table accurate to $0.1 \mathrm{~cm}$ in the supine position without shoes and hats \\
\hline
\end{tabular}

body composition follow-up study at 7 years [54]. Of the 504 women invited only 252 [50\%] consented to participate and therefore, the sample may not be representative of the original recruited women. The results from this study [49] are described narratively.

\section{Quality of RCTs}

The methodological quality of the included trials varied as shown in Fig. 2. Six trials had a low risk of bias in both their random sequence generation and allocation concealment $(55 \%)$ in each domain. Blinding of both participants/staff and outcome assessment were deemed as low risk of bias in four and seven trials, respectively. Over half of the trials were rated as high risk of bias for the completeness of data $(64 \%)$ because of high attrition bias. All trials were deemed to have a low risk of bias for the reported outcomes and five trials were rated as unclear for other potential sources of bias.

\section{Pooled effect of interventions}

The definition of the outcomes in each study, as included in meta-analyses, and their diagnosis method are presented in Table 2.

\section{BMI as outcome measure}

Five trials reported BMI in children and statistically, the studies were largely homogenous $\left(\chi^{2}=1.57, P=0.81\right.$, $I^{2}=0 \%$ ). The pooled results did not show an association between maternal $\omega-3$ LCPUFA intervention during pregnancy and BMI in the offspring (mean difference (SMD) $-0.001,95 \%$ CI - 0.08, 0.08; 2051 children) (Fig. 3).

A sub-group analysis was also conducted including only the studies with comparable duration of follow-up [32, 35, 41]. The results did not yield any significant change (SMD $0.001,95 \%$ CI $-0.089,0.92 ; 1871$ children) (Forest plot not shown).

\begin{tabular}{|c|c|c|c|c|c|c|c|}
\hline Short Title & $\begin{array}{l}\text { Random Sequence } \\
\text { Generation }\end{array}$ & $\begin{array}{l}\text { Allocation } \\
\text { Concealment }\end{array}$ & $\begin{array}{l}\text { Double } \\
\text { Blinding }\end{array}$ & $\begin{array}{l}\text { Blinding of Outcome } \\
\text { Assessment }\end{array}$ & $\begin{array}{l}\text { Incomplete } \\
\text { Outcome Data }\end{array}$ & $\begin{array}{l}\text { Selective Outcome } \\
\text { Reporting }\end{array}$ & $\begin{array}{l}\text { Other Sources } \\
\text { of Bias }\end{array}$ \\
\hline Bergmann (2012) & + & $?$ & $?$ & + & + & + & $?$ \\
\hline Brei (2016) & + & $?$ & - & - & - & + & $?$ \\
\hline Campoy (2011) & $?$ & - & + & $?$ & - & + & $?$ \\
\hline Dunstan (2008) & $?$ & + & + & + & + & + & + \\
\hline Foster 2017 & $?$ & $?$ & $?$ & $?$ & + & + & + \\
\hline Gonzalez-Casanova (2015) & $?$ & + & + & + & - & + & + \\
\hline Helland (2008) & + & $?$ & $?$ & $?$ & - & + & + \\
\hline Muhlhausler (2016) & + & + & $?$ & + & - & + & $?$ \\
\hline Ostadrahimi 2017 & + & + & + & + & + & + & + \\
\hline Rytter (2011) & $?$ & + & - & + & - & + & + \\
\hline Wood (2017) & + & + & $?$ & + & - & + & $?$ \\
\hline
\end{tabular}

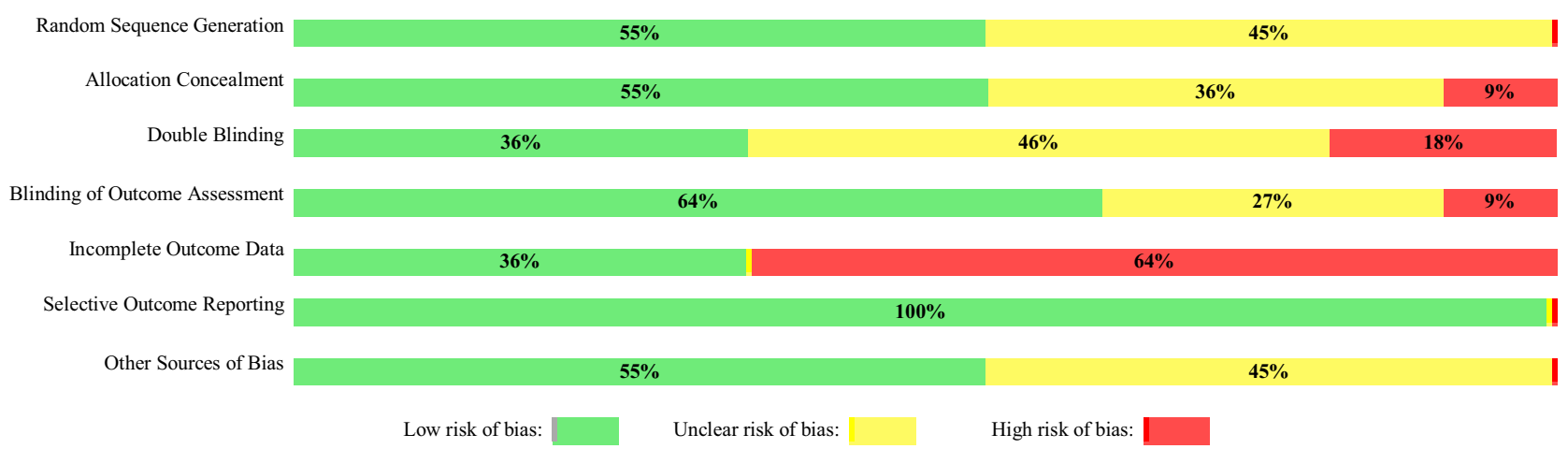

Fig. 2 Risk of bias assessment figure in the included trials 
Fig. 3 Forest plot for prenatal intake of fatty acid vs. placebo for BMI

Heterogeneity: $\mathrm{Q}=1.57 ; \mathrm{df}=4 ; \mathrm{p}=0.814 ; \mathrm{I}$-squared $=0 \%$; tau-squared $=0$

Fixed effect model: $-0.00117(-0.0882,0.0858)$

$\begin{array}{lc}\text { Bergmann (2012) } & 0.145(-0.237 \mid \\ & 0.527) W: 5.2 \\ \text { Campoy (2011) } & 0.156(-0.279 \mid \\ & 0.592) W: 4 \\ \text { Helland (2008) } & -0.117(-0.449 \mid \\ & 0.215) W: 6.9 \\ \text { Muhlhausler (2016) } & -0.006(-0.106 \mid \\ & 0.094) W: 75.4 \\ \text { Rytter (2011) } & -0.027(-0.326 \mid \\ \text { TOTAL: } & 0.2711) W: 8.5 \\ & -0.001(-0.088 \mid \\ & 0.086)\end{array}$

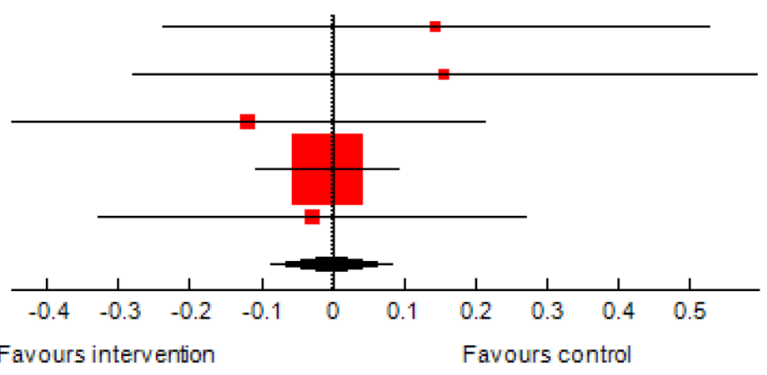

\begin{tabular}{|l|l|l|}
\hline Outcome: BMI & Fatty acid Mean (SD) & Placebo Mean (SD) \\
\hline Bergmann $(\mathrm{n}=41 / 74)$ & $15.7(1.5)$ & $15.5(1.3)$ \\
\hline Campoy $(\mathrm{n}=37 / 45)$ & $17.23(2.92)$ & $16.82(2.30)$ \\
\hline Helland $(\mathrm{n}=82 / 61)$ & $16.4(1.7)$ & $16.3(1.7)$ \\
\hline Muhlhausler $(770 / 761)$ & $16.19(1.61)$ & $16.2(1.73)$ \\
\hline Rytter $(\mathrm{n}=108 / 72)$ & $22.5(3.5)$ & $22.6(3.8)$ \\
\hline Subtotal: $(\mathrm{n}=1,038 / 1,013)$ & & \\
\hline
\end{tabular}

\section{BMI-Z as outcome measure}

The outcome was reported in four trials and moderate heterogeneity was observed between the trials $\left(\chi^{2}=7.26\right.$; $P=0.06 ; I^{2}=58.7 \%$ ). Meta-analysis of these trials did not show an association between maternal $\omega-3$ LCPUFA intervention during pregnancy and BMI-Z in offspring (SMD $0.082,95 \%$ CI $-0.077,0.24 ; 2511$ children) (Fig. 4).

The study by Foster [55] recruited a high-risk sample of pregnant women, with obesity or a history of gestational diabetes and excluding this study from meta-analysis there was no heterogeneity between trials $\left(I^{2}=0 \%\right)$. However the pooled results did not significantly change (SMD 0.0178, 95\% CI - 0.0616, 0.0972) (Forest plot not shown).

\section{Sum of SFT as outcome measure}

Skinfold thickness was reported in three trials and the pooled results showed a high level of heterogeneity between trials $\left(\chi^{2}=38.6, P=4.06, I^{2}=94.8 \%\right)$. The study by Foster [55] only reported a single measure of arm SFT, as opposed to the sum of SFT for 3-4 body points reported in other trials, and given that the study was also conducted in highrisk pregnant women (obese/history of gestational diabetes), we pooled the results excluding this study from the
Fig. 4 Forest plot for prenatal intake of fatty acid vs. placebo for BMI-Z
Heterogeneity: $\mathrm{Q}=7.26 ; \mathrm{df}=3 ; \mathrm{p}=0.064 ; \mathrm{I}$-squared $=58.7 \%$; tau-squared $=0.0132$ Random effects model: $0.0826(-0.0773,0.242)$
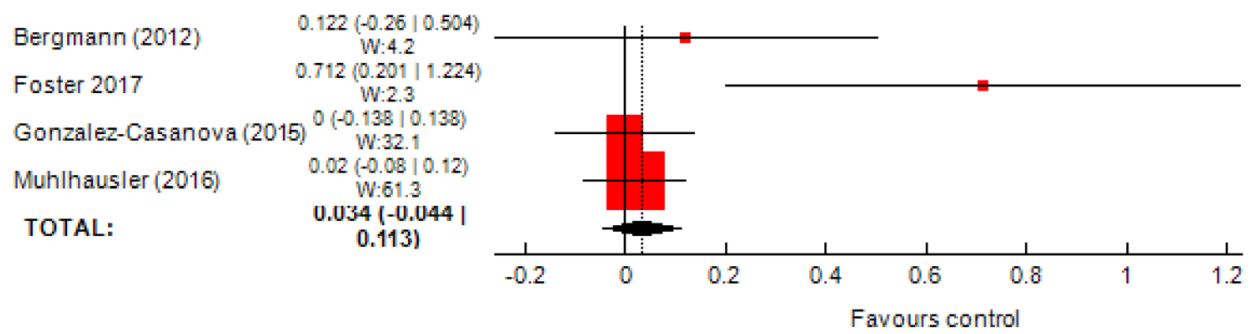

\begin{tabular}{|l|l|l|}
\hline Outcome: BMI-Z & Fatty acid Mean (SD) & Placebo Mean (SD) \\
\hline Bergmann $(\mathrm{n}=41 / 74)$ & $1.02(0.09)$ & $1.01(0.08)$ \\
\hline Foster $(\mathrm{n}=34 / 29)$ & $1.24(0.42)$ & $0.92(0.47)$ \\
\hline Gonzalez-Casanova $(\mathrm{n}=403 / 399)$ & $0.1(1.1)$ & $0.1(1.1)$ \\
\hline Muhlhausler $(770 / 761)$ & $0.56(0.97)$ & $0.54(1.03)$ \\
\hline Subtotal: $(\mathrm{n}=1,248 / 1,263)$ & & \\
\hline
\end{tabular}


meta-analysis. A moderate level of heterogeneity was found between the two trials $\left(\chi^{2}=2.67 ; P=0.10, I^{2}=62.6 \%\right)$ and the meta-analysis did not show an association between maternal $\omega$-3 LCPUFA intervention during pregnancy and sum of SFT in the offspring (SMD 0.09, 95\% CI - 0.33, 0.53, 227 children) (Fig. 5).

\section{Body fat (\%) and fat mass (kg) as outcome measure}

There was no heterogeneity between the two trials reporting these outcomes (body fat (\%): $\chi^{2}=0.10 ; P=0.74, I^{2}=0 \%$ and fat mass: $\left.\chi^{2}=0.24 ; P=0.61, I^{2}=0 \%\right)$. The meta-analyses did not show an association between maternal $\omega-3$ LCPUFA intervention during pregnancy and body fat (\%) (SMD 0.00, 95\% CI - 0.09, 0.09; 1641 children) and fat mass (kg) (SMD 0.01, 95\% CI - 0.08, 0.10; 1641 children) in the offspring (Figs. 6, 7).

\section{Weight as outcome measure}

The outcome was reported in six trials and there was no heterogeneity between studies $\left(\chi^{2}=2.08 ; P=0.83, I^{2}=0 \%\right)$.
The results of meta-analysis did not show an association between maternal $\omega$-3 LCPUFA intervention during pregnancy and weight in offspring (SMD 1.01, 95\% CI - 0.056, 0.091; 2746) (Fig. 8).

A sub-group analysis was also conducted including the study conducted by Brei et al. [47], which defined "standard diet" as its comparator. The studies were largely homogenous $\left(I^{2}=0 \%\right)$ and the meta-analysis did not alter the results greatly (SMD 0.026, 95\% CI - 0.046, 0.099) (Forest plot not shown).

In the study by Ostadrahimi children were followed-up by 6 months of age [56] and thus, weight was reported as a growth measure. Since the study had the shortest followup duration compared to the other included trials, a metaanalysis was conducted excluding this study and did not alter the results (SMD 0.009, 95\% CI $-0.0669,0.0854$ ).

\section{Height as outcome measure}

The outcome was reported in six trials and statistically, there was no heterogeneity between studies $\left(\chi^{2}=2.97 ; P=0.70\right.$, $\left.I^{2}=0 \%\right)$. The results of meta-analysis did not show an
Fig. 5 Forest plot for prenatal intake of fatty acid vs. placebo for sum of SFT
Fig. 6 Forest plot for prenatal intake of fatty acid vs. placebo for body fat $(\%)$
Heterogeneity: $\mathrm{Q}=2.67 ; \mathrm{df}=1 ; \mathrm{p}=0.102 ; \mathrm{I}$-squared $=62.6 \%$; tau-squared $=0.062$

Random effects model: $0.0968(-0.339,0.533)$

Bergmann (2012)
Brei (2016)
TOTAL:
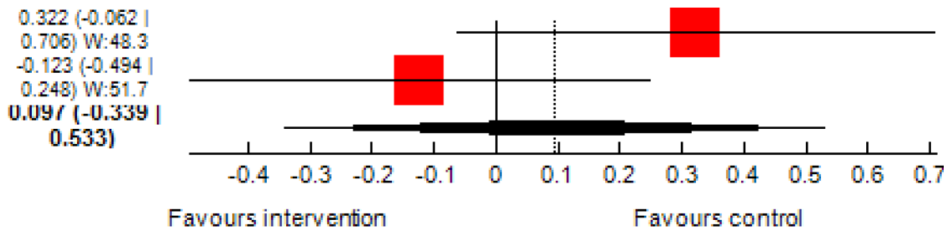

\begin{tabular}{|l|l|l|}
\hline Outcome: Sum of SFT & Fatty acid Mean (SD) & Placebo Mean (SD) \\
\hline Bergmann $(\mathrm{n}=41 / 74)$ & $23.2(7.1)$ & $21.1(6.1)$ \\
\hline Brei $(\mathrm{n}=57 / 55)$ & $23.9(4.7)$ & $24.5(5.0)$ \\
\hline Subtotal: $(\mathrm{n}=98 / 129)$ & & \\
\hline
\end{tabular}

Heterogeneity: $\mathrm{Q}=0.103 ; \mathrm{df}=1 ; \mathrm{p}=0.749 ; \mathrm{I}$-squared $=0 \%$; tau-squared $=0$. Fixed effect model: $0.00169(-0.095,0.0984)$

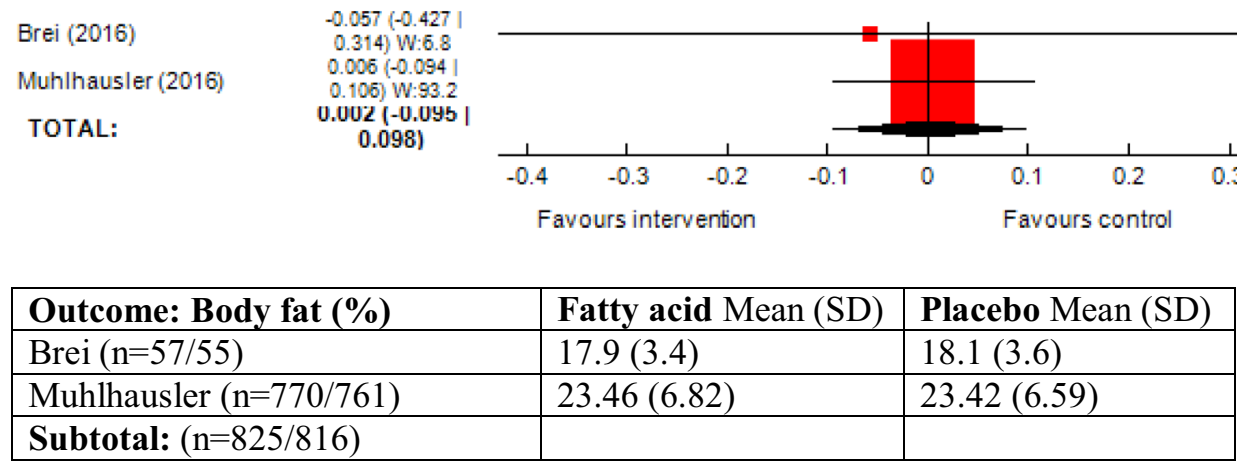


Fig. 7 Forest plot for prenatal intake of fatty acid vs. placebo for fat mass $(\mathrm{kg})$
Heterogeneity: $\mathrm{Q}=0.247 ; \mathrm{df}=1 ; \mathrm{p}=0.619 ;$ I-squared $=0 \%$; tau-squared $=0$. Fixed effect model: $0.0121(-0.0846,0.109)$

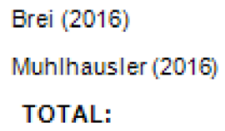

Favours intervention

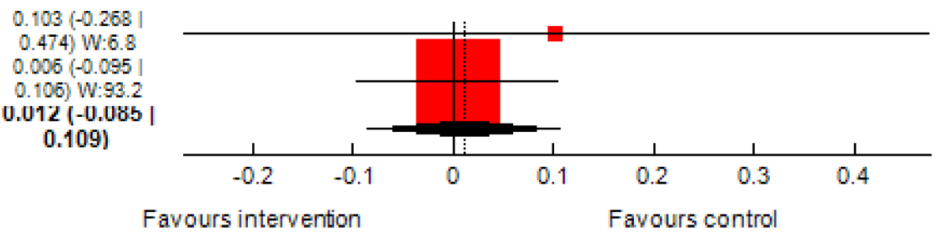

\begin{tabular}{|l|l|l|}
\hline Outcome: Fat mass (kg) & Fatty acid Mean (SD) & Placebo Mean (SD) \\
\hline Brei $(\mathrm{n}=57 / 55)$ & $3.5(1.1)$ & $3.4(0.8)$ \\
\hline Muhlhausler $(\mathrm{n}=770 / 761)$ & $4.75(1.78)$ & $4.74(1.85)$ \\
\hline Subtotal: $(\mathrm{n}=825 / 816)$ & & \\
\hline
\end{tabular}

Fig. 8 Forest plot for prenatal intake of fatty acid vs. placebo for weight
Heterogeneity: $\mathrm{Q}=2.08 ; \mathrm{df}=5 ; \mathrm{p}=0.837$; I-squared $=0 \%$; tau-squared $=0$ Fixed effect model: $0.0174(-0.0568,0.0915)$

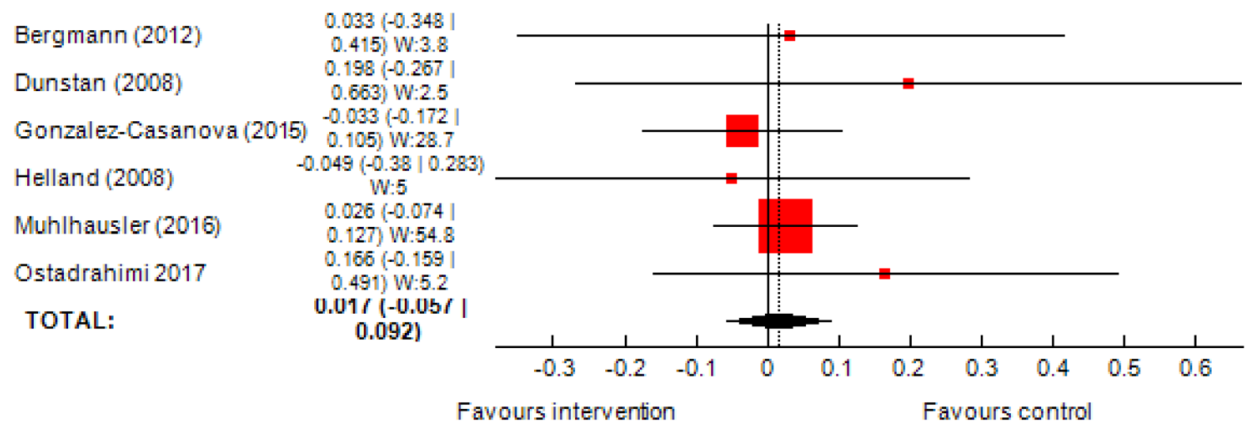

\begin{tabular}{|l|l|l|}
\hline Outcome: Weight & Fatty acid Mean (SD) & Placebo Mean (SD) \\
\hline Bergmann $(\mathrm{n}=41 / 74)$ & $22.4(3.1)$ & $22.3(2.9)$ \\
\hline Dunstan $(\mathrm{n}=33 / 39)$ & $14.5(2.0)$ & $14.1(2.0)$ \\
\hline Gonzalez-Casanova $(\mathrm{n}=369 / 370)$ & $10.4(1.1)$ & $10.4(1.2)$ \\
\hline Helland $(\mathrm{n}=82 / 61)$ & $26.8(4.1)$ & $27.0(4.1)$ \\
\hline Muhlhausler $(770 / 761)$ & $19.95(3.0)$ & $19.87(3.07)$ \\
\hline Ostadrahimi $(\mathrm{n}=75 / 71)$ & $7.98(0.83)$ & $7.84(0.85)$ \\
\hline Subtotal: $(\mathrm{n}=1,370 / 1,376)$ & & \\
\hline
\end{tabular}

association between maternal $\omega-3$ LCPUFA intervention during pregnancy and height in offspring (SMD 0.01, 95\% CI - 0.06, 0.08; 2746) (Fig. 9).

A sub-group analysis was also conducted including the study conducted by Brei et al. [47], which defined "standard diet" as its comparator. The studies were largely homogenous $\left(I^{2}=0 \%\right)$ and the meta-analysis did not alter the results greatly (SMD 0.025, 95\% CI -0.046, 0.098) (Forest plot not shown).

In the study by Ostadrahimi children were followed-up by 6 months of age [56] and thus, height was reported as a growth measure. Since the study had the shortest follow-up duration compared to the other included trials, a meta-analysis was conducted excluding this study and did not alter the results (SMD 0.009, 95\% CI -0.066, 0.086).

\section{Weight $Z$ score and height $Z$ score as outcome measures}

Two trials by Gonzalez-Casanova et al. [44] and Foster et al. [55] reported these outcomes and pooling the results, the trials were largely heterogeneous (weight $Z$ score: $\chi^{2}=11$; $P=0.00, I^{2}=90.9 \%$ and height $Z$ score: $\chi^{2}=8.61 ; P=0.003$, $\left.I^{2}=88.4 \%\right)$. There were no associations between maternal $\omega$-3 LCPUFA intervention during pregnancy and weight $Z$ score and height $Z$ score (Forest plots not shown). 
Fig. 9 Forest plot for prenatal intake of fatty acid vs. placebo for height

Heterogeneity: $\mathrm{Q}=2.97 ; \mathrm{df}=5 ; \mathrm{p}=0.705 ; \mathrm{I}$-squared $=0 \%$; tau-squared $=0$

Fixed effect model: $0.0133(-0.0608,0.0875)$

$\begin{array}{lc} & -0.082(-0.464 \mid 0.3) \\ \text { Bergmann (2012) } & \text { W:3.8 } \\ \text { Dunstan (2008) } & 0.116(-0.348 \mid 0.58) \\ & W: 2.6 \\ \text { Gonzalez-Casanova }(2015) & -0.022(-0.161 \mid \\ & 0.116) W: 28.7 \\ & -0.207(-0.539 \mid \\ \text { Helland (2008) } & 0.126) W: 5 \\ & 0.048(-0.052 \mid \\ \text { Muhlhausler (2016) } & 0.148) W: 54.8 \\ & 0.075(-0.25 \mid 0.399) \\ \text { Ostadrahimi 2017 } & W: 5.2 \\ & 0.013(-0.061 \mid \\ \text { TOTAL: } & 0.087)\end{array}$

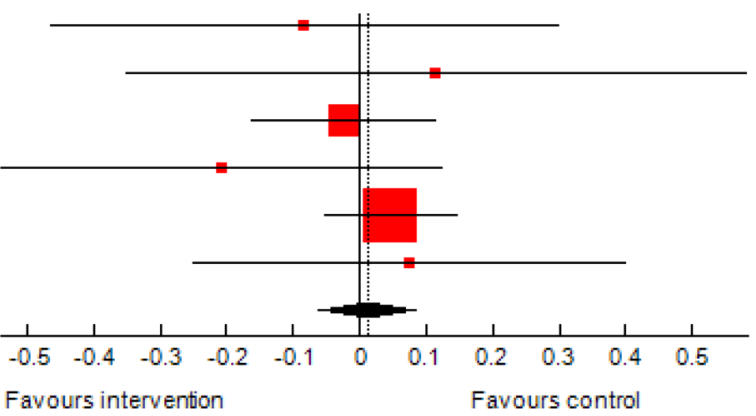

\begin{tabular}{|l|l|l|}
\hline Outcome: Height & Fatty acid Mean (SD) & Placebo Mean (SD) \\
\hline Bergmann $(\mathrm{n}=41 / 74)$ & $119.2(5.3)$ & $119.6(4.6)$ \\
\hline Dunstan $(\mathrm{n}=33 / 39)$ & $93.8(3.8)$ & $93.3(4.6)$ \\
\hline Gonzalez-Casanova $(\mathrm{n}=369 / 370)$ & $108.3(4.4)$ & $108.4(4.5)$ \\
\hline Helland $(\mathrm{n}=82 / 61)$ & $127.5(5.5)$ & $128.6(5.0)$ \\
\hline Muhlhausler $(770 / 761)$ & $110.82(5.06)$ & $110.58(4.93)$ \\
\hline Ostadrahimi $(75 / 71)$ & $67.1(2.9)$ & $66.9(2.4)$ \\
\hline Subtotal: $(\mathrm{n}=1,370 / 1,376)$ & & \\
\hline
\end{tabular}

Table 3 List of the reported clinical outcomes in Wood 2017 study [54]

\begin{tabular}{lccc}
\hline & $\begin{array}{l}\text { DHA }(n=132) \\
\text { Mean (SD) }\end{array}$ & $\begin{array}{l}\text { Control }(n=118) \\
\text { Mean (SD) }\end{array}$ & $P$ value \\
\hline BMI & $16.48(2.3)$ & $16.25(2.56)$ & 0.46 \\
BMI-Z & $0.43(1.07)$ & $0.25(1.19)$ & 0.22 \\
Weight (kg) & $25.18(4.52)$ & $25.36(5.31)$ & 0.77 \\
Height (cm) & $123.3(5.11)$ & $124.6(5.71)$ & 0.07 \\
Body fat (\%), BOD & $19.19(6.89)$ & $19.61(7.63)$ & 0.58 \\
$\quad$ POD & & & \\
Body fat (\%), BIS & $24.22(7.42)$ & $22.78(6.68)$ & 0.11 \\
Fat mass (kg), BOD & $5.2(3.0)$ & $5.12(3.33)$ & 0.86 \\
$\quad$ POD & & & \\
Fat mass (kg), BIS & $6.28(2.9)$ & $5.99(3.18)$ & 0.46 \\
\hline
\end{tabular}

\section{Description of the outcomes reported in Wood et al. [54] study}

This study reported body composition results at 7 years follow-up in a sub-sample of total recruited pregnant women in Adelaide centres from the original study [53]. Body composition measurements were assessed using two methods of Air Displacement Plethysmography (BOD POD system) and BIS (Table 3). The results suggest that the maternal $\omega-3$ LCPUFA intervention during pregnancy did not have an influence on childhood anthropometric and body composition measures at 7 years follow-up.

\section{Discussion}

Eleven RCTs were identified, with a total number of 3644 children whose mothers started supplementation with $\omega-3$ LCPUFA during pregnancy and for whom obesity and growth measures were followed-up during childhood. Trials were heterogeneous for their sample, reported outcomes and duration of follow-up. Random sequence generation was deemed to be adequate in six of the included trials. Two and five trials were also judged to have a high and unclear risk of bias respectively for their performance bias and additionally, seven trials had a high attrition bias. The findings from this systematic review and meta-analyses did not provide evidence that intake of $\omega-3$ LCPUFA during pregnancy could protect against subsequent development of a number of childhood obesity outcomes i.e. BMI, BMI-Z, weight, height, sum of SFT, body fat (\%) and fat mass $(\mathrm{kg})$. Overall, the results from this review need to be considered with caution because of the large heterogeneities observed between studies and also in light of the assessment for risk of bias. It is also worth mentioning that only two trials $[47,56]$ were initially designed to assess growth and obesity measures in children following maternal $\omega$-3 LCPUFA supplementation during pregnancy. The results are consistent with those of the meta-analyses; neither found a significant difference between the study arms for growth measures at 6 months [56] and obesity measures at 5 years [47] follow-ups. 


\section{Overall completeness and applicability of evidence}

There was no evidence that $\omega-3$ LCPUFA supplementation during pregnancy is effective for prevention of obesity in the offspring. The heterogeneity between the trials limited the findings and where statistical heterogeneities exist, random effect models were used to pool the results. Heterogeneity between studies originated from variations in: dosage and timing of intervention, comparators, methods for reporting the outcome measures across studies, locations/settings and the follow-up duration. One study [39] also used DHA, isolated from algae, which may act differently from fish oil [58]. It was not possible to conduct stratified analyses for the type, dosage and timing of intervention to explore the differences due to the relatively small number of trials in each group. In addition, although most studies recruited a relatively large sample, only a small number of participants agreed to participate or could be approached at follow-up assessments.

\section{Quality of evidence}

Overall, the trials were at moderate to high risk of bias (Fig. 2). Randomisation and allocation concealment were deemed as unclear for $45 \%$ and $36 \%$ of included studies respectively. High loss to follow-up was also a major concern where $64 \%$ of studies showed high attrition which might have largely biased the effect of intervention within these trials. In addition, not many studies have reported these outcomes in the context of maternal $\omega$-3 LCPUFA intervention during pregnancy. Also, measures of obesity and growth such as BMI and weight were the most reported outcomes in trials and the use of more precise methods for measurement of obesity in children such as MRI/ultrasound techniques and skinfold thickness, as sum or single measure, were reported in only a few trials $[41,47]$.

\section{Strengths and limitations}

This systematic review only included trials in which maternal $\omega$-3 LCPUFA supplementation was commenced during pregnancy, thus, crucially, enabling the effect of $\omega-3$ LCPUFA intervention during pregnancy for prevention of childhood obesity to be isolated. Also following an a priori published protocol, a comprehensive search strategy allowed for a complete coverage of all the relevant literature through citation databases, trial registries and conference proceedings with no limitation by language or publication status. Moreover, a range of obesity and growth measures were the focus of the present review and the most up-to-date results from the trials, reported as the longest available follow-up data, are included in the meta-analyses. A limitation of the review is that sub-group analyses were not conducted as planned e.g. duration of intervention, dosage of $\omega$-3 LCPUFA because of the limited number of studies that could contribute in the meta-analyses.

\section{Consistency with other reviews}

Although similar systematic reviews have been conducted, they have either examined fatty acid supplementation during the prenatal period and also exclusively in breastfeeding [23, 24] or have only examined outcomes at birth [22]. Also, other reviews on this topic have narratively described the effectiveness of prenatal and postnatal supplementation with $\omega-3$ LCPUFA on an infant's body composition [19-21]. The review by Stratakis et al. [23] conducted meta-analyses only on BMI for different age groups, although the review by $\mathrm{Li}$ et al. [24] assessed a wide range of obesity measures in children e.g. BMI, weight, sum of SFT.

The main distinction of this systematic review is that it examined intake of $\omega$-3 LCPUFA commenced during pregnancy and (where applicable) continued postnatally, examining a wide range of obesity and growth measures. The findings from this systematic review did not support the hypothesis that maternal $\omega-3$ LCPUFA could protect against obesity-related measures in offspring. We have also reported methodological shortcomings including number of studies, small sample sizes and attrition bias.

\section{Authors' conclusion}

\section{Implications for practice}

The results of the current systematic review do not provide an evidence for the prevention of obesity in the offspring by maternal $\omega-3$ LCPUFA intervention during pregnancy when compared with placebo/no treatment. Due to the high heterogeneity between studies along with small sample size and large attrition at follow-ups, the effects of $\omega$-3 LCPUFA supplementation during pregnancy for prevention of childhood adiposity in the long-term remains unclear.

\section{Implications for research}

While the meta-analyses conducted as part of this systematic review did not support the effectiveness of $\omega$-3 LCPUFA supplementation during pregnancy and lactation on childhood obesity, the heterogeneity in all aspects of the included trials makes it difficult to determine whether this is due to the lack of an effect, or differences in study design. Hence, the effect of maternal $\omega-3$ LCPUFA intervention during pregnancy for prevention of childhood obesity need to be further investigated in large, high quality RCTs. Further research need also to determine specific sub-groups in the 
population that might get a greater benefit and whether different omega-3 LCPUFA i.e. EPA vs. DHA might potentially have different effects.

Given that only two included studies had been established to explicitly examine the effect of maternal $\omega-3$ LCPUFA intervention during pregnancy on obesity in offspring, such RCTs need to be designed specifically to examine this question. Trials should also consider the effect of $\omega-6 / \omega-3$ ratio in the dietary intervention and, rather than increasing $\omega-3$ LCPUFA in isolation, to determine the role of the balance of fatty acid intake in maternal diet. Using combined methods of anthropometric and SFT measurement as well as more precise measures such as MRI and ultrasound will also allow for more accurate estimation of adipose tissue deposition in children.

The optimal timing of $\omega$-3 LCPUFA intervention in pregnancy is another key factor that needs to be further investigated. The first appearance of adipocytes in the human foetus occurs in second trimester of pregnancy, between 14 and 16 weeks of gestation [17]. Further research is required to determine the critical window for programming of offspring adipose tissue. Baseline level of DHA in pregnant women, type and optimal dose of $\omega-3$ LCPUFA, as well as the choice of control regimens, are elements that need to be considered in further trials. More importantly, additional rigorous strategies are needed to minimise the low participation rate at follow-up assessments. Recruiting fewer participants or high attrition rates in interventions with $\omega-3$ PUFAs could lead to significantly varied findings and thus bias in impact of fatty acids, as highlighted in a recent study [59]. Therefore, longitudinal studies with adequate sample size and repeated measurements are required to provide strong evidence with which to determine the effect of $\omega$-3 LCPUFA intake during pregnancy on obesity in offspring. Furthermore, the majority of the studies were conducted in developed countries; it remains a priority to also understand the effectiveness of these interventions for childhood obesity among underreported populations.

\section{Compliance with ethical standards}

Conflict of interest On behalf of all authors, the corresponding author states that there is no conflict of interest.

Open Access This article is distributed under the terms of the Creative Commons Attribution 4.0 International License (http://creativeco mmons.org/licenses/by/4.0/), which permits unrestricted use, distribution, and reproduction in any medium, provided you give appropriate credit to the original author(s) and the source, provide a link to the Creative Commons license, and indicate if changes were made.

\section{References}

1. European Association for the Study of Obesity (2015) Obesity facts \& figures obesity facts \& figures: useful resources from the WHO Regional Office for Europe. Obesity facts \& figures: World Health Organisation Fact sheet. European Association for the Study of Obesity, Vienna

2. Egan KB, Ettinger AS (2013) Childhood body mass index and subsequent physician-diagnosed asthma: a systematic review and meta-analysis of prospective cohort studies. BMC Pediatr 13:121

3. Paulis WD, Silva S, Koes BW, Van Middelkoop M (2014) Overweight and obesity are associated with musculoskeletal complaints as early as childhood: a systematic review. Obes Rev 15:52-67

4. The N, Richardson A, Gordon-Larsen P (2013) Timing and duration of obesity in relation to diabetes: findings from an ethnically diverse, nationally representative sample. Diabetes Care 36:865-872

5. Barker DJ (1997) Fetal nutrition and cardiovascular disease in later life. Br Med Bull 53(1):96-108

6. Barker DJ (2012) Developmental origins of chronic disease. Public Health 126:185-189

7. Mayor RS, Finch KE, Zehr J et al (2015) Maternal high-fat diet is associated with impaired fetal lung development. Am J Physiol Lung Cell Mol Physiol 309:L360-L368

8. Campbell DM, Hall MH, Barker DJP, Cross J, Shiell AW, Godfrey KM (1996) Diet in pregnancy and the offspring's blood pressure 40 years later. BJOG Int J Obstet Gynaecol 103:273-280

9. Jansson T, Powell TL (2007) Role of the placenta in fetal programming: underlying mechanisms and potential interventional approaches. Clin Sci 113:1-13

10. Ravelli CJ, Vandermeulen JHP, Michels RPJ, Osmond C, Barker DJP, Hales CN, Bleker OP (1998) Glucose-tolerance in adults after prenatal exposure to famine. Lancet 351:173-177

11. Ailhaud G, Massiera F, Weill P (2006) Temporal changes in dietary fats: role of $n-6$ polyunsaturated fatty acids in excessive adipose tissue development and relationship to obesity. Prog Lipid Res 45:203-236

12. Donahue SMA, Rifs-Shiman ShL, Gold DR, Jouni ZE, Gillman MW, Oken E (2011) Prenatal fatty acid status and child adiposity at age 3: results from a US pregnancy cohort. Am J Clin Nutr 93:780-788

13. Moon RJ, Harvey NC, Robinson SM, Ntani G, Davis JH, Inskip $\mathrm{HM}$ et al (2013) Maternal plasma polyunsaturated fatty acid status in late pregnancy is associated with offspring body composition in childhood. J Clin Endocrinol Metab 98:299-307

14. Muhlhausler BS, Ailhaud GP (2013) Omega-6 polyunsaturated fatty acids and the early origins of obesity. Curr Opin Endocrinol Diabetes Obes 20:56-61

15. Hussey B, Lindley MR, Mastana SS (2017) Omega 3 fatty acids, inflammation and DNA methylation: an overview. Clin Lipidol $12: 24-32$

16. Flachs P, Rossmeisl M, Bryhn M, Kopecky J (2009) Cellular and molecular effects of $n-3$ polyunsaturated fatty acids on adipose tissue biology and metabolism. Clin Sci 116:1-16

17. Ailhaud G, Hauner H (2004) Development of white adipose tissue. 2nd. Ed. In: Bouchard C, Bray GA (eds) Handbook of obesity, etiology and pathophysiology. Marcel Dekker, New York, pp 481-514

18. Spalding KL, Arner E, Westermark PO (2008) Dynamics of fat cell turnover in humans. Nature 453:783-787

19. Muhlhausler BS, Gibson RA, Makrides M (2010) Effect of long-chain polyunsaturated fatty acid supplementation during pregnancy or lactation on infant and child body composition: a systematic review. Am J Clin Nutr 92:857-863 
20. Campoy C, Escolano-Margarit MV, Anjos T, Szajewska H, Uauy R (2012) Omega 3 fatty acids on child growth, visual acuity and neurodevelopment. Br J Nutr 107:S85-S106

21. Rodriguez G, Iglesia I, Bel-Serrat S, Moreno LA (2012) Effect of $\mathrm{n}-3$ long chain polyunsaturated fatty acids during the perinatal period on later body composition. Br J Nutr 107:S117-S128

22. Imhoff-Kunsch B, Briggs V, Goldenberg T, Ramakrishnan U (2012) Effect of n-3 long-chain polyunsaturated fatty acid intake during pregnancy on maternal, infant, and child health outcomes: a systematic review. Paediatr Perinat Epidemiol 26(SUPPL. 1):91-107

23. Stratakis N, Gielen M, Chatzi L, Zeegers MP (2014) Effect of maternal n-3 long-chain polyunsaturated fatty acid supplementation during pregnancy and/or lactation on adiposity in childhood: a systematic review and meta-analysis of randomized controlled trials. Eur J Clin Nutr 68:1277-1287

24. Li G, Chen H, Zhang W, Tong O, Yan Y (2017) Effects of maternal omega-3 fatty acids supplementation during pregnancy/lactation on body composition of the offspring: a systematic review and meta-analysis. Clin Nutr (Epub ahead of print)

25. Lefebvre C, Manheimer E, Glanville J (2011) Chap. 6: Searching for studies. In: Higgins JPT, Green S (eds) Cochrane handbook for systematic reviews of interventions version 5.1.0 (updated March 2011). The Cochrane Collaboration. http://handbook-5-1. cochrane.org/. Accessed 25 Mar 2018

26. Higgins JPT, Altman DG, Sterne JAC (2011) Chap. 8: Assessing risk of bias in included studies. In: Higgins JPT, Green S (eds) Cochrane handbook for systematic reviews of interventions version 5.1.0 (updated March 2011). The Cochrane Collaboration. http://handbook-5-1.cochrane.org/. Accessed 25 Mar 2018

27. Higgins JPT, Deeks JJ, Altman DG (2011) Chap. 16: Special topics in statistics. In: Higgins JPT, Green S (eds) Cochrane handbook for systematic reviews of interventions version 5.1.0 (updated March 2011). The Cochrane Collaboration. http://handb ook-5-1.cochrane.org/. Accessed 25 Mar 2018

28. Sterne JA, Egger M, Smith GD (2001) Systematic reviews in health care: investigating and dealing with publication and other biases in meta-analysis. BMJ 323:101-105

29. Deeks JJ, Higgins JPT, Altman DG (2011) Chap. 9: Analysing data and undertaking meta-analyses. In: Higgins JPT, Green S (eds) Cochrane handbook for systematic reviews of interventions version 5.1.0 (updated March 2011). The Cochrane Collaboration. http://handbook-5-1.cochrane.org/. Accessed 25 Mar 2018

30. Helland IB, Saugstad OD, Smith L, Saarem K, Solvoll K, Ganes T, Drevon CA (2001) Similar effects on infants of n-3 and n-6 fatty acids supplementation to pregnant and lactating women. Pediatrics 108:1-10

31. Helland IB, Smith L, Blomen B, Saarem K, Saugstad OD, Drevon CA (2008) Effect of supplementing pregnant and lactating mothers with n-3 very-long-chain fatty acids on children's IQ and body mass index at 7 years of age. Pediatrics 122:e472-e479

32. Dunstan JA, Mori TA, Barden A, Beilin LJ, Taylor AL, Holt PG, Prescott SL (2003) Fish oil supplementation in pregnancy modifies neonatal allergen-specific immune responses and clinical outcomes in infants at high risk of atopy: a randomized, controlled trial. J Allergy Clin Immunol 112:1178-1184

33. Dunstan JA, Roper J, Mitoulas L, Hartmann PE, Simmer K, Prescott SL (2004) The effect of supplementation with fish oil during pregnancy on breast milk immunoglobulin A, soluble CD14, cytokine levels and fatty acid composition. Clin Exp Allergy 34:1237-1242

34. Dunstan JA, Simmer K, Dixon G, Prescott SL (2008) Cognitive assessment of children at age $21 / 2$ years after maternal fish oil supplementation in pregnancy: a randomised controlled trial. Arch Dis Child Fetal Neonatal Ed 93:F45-F50
35. Campoy C, Escolano-margarit MV, Ramos R, Porrilla-Roure M, Csabi G, Beyer J et al (2011) Effects of prenatal fish-oil and 5-methyltetrahydrofolate supplementation on cognitive development of children at 6.5 y of age $1-5$. Am J Clin Nutr 94:1880-1888

36. Decsi T, Campoy C, Koletzko B (2005) Effect of N-3 polyunsaturated fatty acid supplementation in pregnancy: the Nuheal trial. Adv Exp Med Biol 569:109-113

37. Escolano-margarit MV, Ramos R, Beyer J (2011) Prenatal DHA status and neurological outcome in children at age 5.5 years are positively associated. J Nutr 141:1216-1223

38. Krauss-Etschmann S, Shadid R, Campoy C, Hoster E, Demmelmair H, Jiménez M et al (2007) Effects of fish-oil and folate supplementation of pregnant women on maternal and fetal plasma concentrations of docosahexaenoic acid and eicosapentaenoic acid: a European randomized multicenter trial. Am J Clin Nutr 85:1392-1400

39. Rytter D, Bech BH, Christensen JH, Schmidt EB, Henriksen TB, Olsen SF (2011) Intake of fish oil during pregnancy and adiposity in 19-y-old offspring: follow-up on a randomized controlled trial. Am J Clin Nutr 94:701-708

40. Olsen SF, Sorensen JD, Secher NJ, Hedegaard M, Henriksen TB, Hansen HS, Grant A (1992) Randomised controlled trial of effect of fish-oil supplementation on pregnancy duration. Lancet 339:1003-1007

41. Bergmann RL, Bergmann KE, Richter R, Haschke-Becher E, Henrich W, Dudenhausen JW (2012) Does docosahexaenoic acid (DHA) status in pregnancy have any impact on postnatal growth? Six-year follow-up of a prospective randomized double-blind monocenter study on low-dose DHA supplements. J Perinat Med 40:677-684. https://doi.org/10.1515/jpm-2012-0080

42. Bergmann R, Bergmann KE, Haschke-Becher E, Richter R, Dudenhausen JW, Barclay D, Haschke F (2007) Does maternal docosahexaenoic acid supplementation during pregnancy and lactation lower BMI in late infancy? J Perinat Med 35:295-300

43. Bergmann RL, Haschke-Becher E, Klassen-Wigger P, Bergmann KE, Richter R, Dudenhausen JW et al (2008) Supplementation with $200 \mathrm{mg} /$ day docosahexaenoic acid from mid-pregnancy through lactation improves the docosahexaenoic acid status of mothers with a habitually low fish intake and of their infants. Ann Nutr Metab 52:157-166

44. Gonzalez-Casanova I, Stein AD, Hao W, Garcia-Feregrino R, Barraza-Villarreal A, Romieu I et al (2015) Prenatal supplementation with docosahexaenoic acid has no effect on growth through 60 months of age. J Nutr 145:1330-1334

45. Ramakrishnan U, Stein AD, Parra-Cabrera S, Wang M, ImhoffKunsch B, Juarez-Marquez S et al (2010) Effects of docosahexaenoic acid supplementation during pregnancy on gestational age and size at birth: randomized, double-blind, placebo-controlled trial in Mexico. Food Nutr Bull 31:S108-S116

46. Stein AD, Wang M, Martorell R, Neufeld LM, Flores-Ayala R, Rivera JA, Ramakrishnan U (2011) Growth to age 18 months following prenatal supplementation with docosahexaenoic acid differs by maternal gravidity in Mexico. J Nutr 141:316-320

47. Brei C, Stecher L, Much D, Karla MT, Amann-gassner U, Shen J et al (2016) Effect of reducing the n-6:n-3 long-chain PUFA ratio during pregnancy and lactation on infant adipose tissue growth within the first year of life : an open-label randomized controlled trial. Am J Clin Nutr 103:1472-1481

48. Hauner H, Much D, Vollhardt C, Brunner S, Schmid D, Sedlmeier E et al (2012) Effect of reducing the n-6:n-3 long-chain PUFA ratio during pregnancy and lactation on infant adipose tissue growth within the first year of life: an open-label randomized controlled trial. Am J Clin Nutr 95:383-394 
49. Brunner S, Schmid D, Hüttinger K, Much D, Heimberg E, Sedlmeier EM et al (2013) Maternal insulin resistance, triglycerides and cord blood insulin in relation to post-natal weight trajectories and body composition in the offspring up to 2 years. Diabet Med 30:1500-1507. https://doi.org/10.1111/dme.12298

50. Much D, Brunner S, Vollhardt C, Schmid D, Sedlmeier EM, Brüderl M et al (2013) Breast milk fatty acid profile in relation to infant growth and body composition: results from the INFAT study. Pediatr Res 74:230-237

51. Brunner S, Schmid D, Zang K, Much D, Knoeferl B, Kratzsch J et al (2015) Breast milk leptin and adiponectin in relation to infant body composition up to 2 years. Pediatr Obes 10:67-73

52. Muhlhausler BS, Yelland LN, McDermott R, Tapsell L, McPhee AJ, Gibson RA, Makrides M (2016) DHA supplementation during pregnancy does not reduce BMI or body fat mass in children: follow-up of the DOMInO randomized controlled trial. Am J Clin Nutr 103:1489-1496

53. Makrides M, Gibson RA, McPhee AJ, Yelland L, Quinlivan J, Ryan P et al (2010) Effect of DHA supplementation during pregnancy on maternal depression and neurodevelopment of young children: a randomized controlled trial. JAMA J Am Med Assoc 304:1675-1683

54. Wood K, Mantzioris E, Lingwood B, Couper J, Makrides M, Gibson RA, Muhlhausler BS (2017) The effect of maternal DHA supplementation on body fat mass in children at 7 years: follow-up of the DOMInO randomized controlled trial. Prostaglandins Leukot Essent Fatty Acids. https://doi.org/10.1016/j.plefa.2017.09.013

55. Foster BA, Escaname E, Powell TL, Larsen B, Siddiqui SK, Menchaca J et al (2017) Randomized controlled trial of DHA supplementation during pregnancy: child adiposity outcomes. Nutrients 9:566-575

56. Ostadrahimi A, Salehi-pourmehr H, Mohammad-AlizadehCharandabi S, Heidarabady S, Farshbaf-Khalili A (2017) The effect of perinatal fish oil supplementation on neurodevelopment and growth of infants: a randomized controlled trial. Eur J Nutr. https://doi.org/10.1007/s00394-017-1512-1 (Epub ahead of print)

57. Ostadrahimi A, Mohammad-Alizadeh S, Mirghafourvand M, Farshbaf-Khalili S, Jafarilar-Agdam N, Farshbaf-Khalili A (2017) The effect of fish oil supplementation on maternal and neonatal outcomes: a triple-blind, randomized controlled trial. J Perinat Med 45:1069-1077

58. Geels G, Bishop KS, Ferguson LR (2013) Alternative sources of omega-3 fats: can we find a sustainable substitute for fish? Nutrients 5:1301-1315

59. Yelland LN, Makrides M, McPhee AJ, Quinlivan J, Gibson RA (2016) Importance of adequate sample sizes in fatty acid intervention trials. Prostaglandins Leukot Essent Fatty Acids 107:8-11 